\title{
Organizational Alignment in Ict Company in the Republic of Macedonia
}

\author{
Marjan Bojadziev \\ University American College Skopje, Macedonia \\ Ana Tomovska Misoska (Corresponding author) \\ University American College Skopje, Macedonia \\ Antoni Pesev \\ Ultra Computers, Macedonia \\ Miodraga Stefanoska Petkovska \\ University American College Skopje, Macedonia \\ E-mail: tomovska@uacs.edu.mk
}

Received: November 4, 2016 Accepted: November 30, 2016

doi:10.5296/ber.v6i2.10258

URL: http://dx.doi.org/10.5296/ber.v6i2.10258

\begin{abstract}
This article focuses on organizational alignment as a very important aspect of the organizational functioning. Organizational alignment is a complex concept and is sparsely researched and measured especially in South East Europe. There are different theoretical views on alignment but most of them focus on organizational culture, the values and the structure and strategy as main elements of alignment. Therefore, the model outlined in the paper, Vox Organizationis, proposes that the alignment should be achieved between the non-formal aspects of the organizational functioning appraised by the organizational culture as seen by the employees and the values of the organizational leader as non-formal aspects of the organizational functioning, and the formal aspect visible in the strategy, structure and policies of the organization. The paper presents a case study of one company from the ICT sector in the Republic of Macedonia to show the application and the usefulness of the model. The results in that company show good levels of overall alignment with few areas that need
\end{abstract}


improvement. The significance of the paper is not only in outlining the results of the case study company, but also in showing the applicability of the model in achieving better organizational alignment.

Keywords: Organizational alignment, ICT Company, Vox Organizationis

\section{Introduction}

Organizational alignment is one of the aspects of organizational functioning that is getting increased attention from scientists and managers. The concept is thought to be contributing to employee engagement (Biggs Brough \& Barbour, 2014), quality of the organizational performance (Merron, 1994), improvement of organizational effectiveness (Biggs et.al., 2014; Powell, 1992; Tosti \& Jackson, 1994) and the successful organizational functioning (Andrews \& Beynon, 2011; Crots \& Ford, 2008; Denison \& Mishra, 1989; Dickson, Aditya \& Chhokar, 2000). Although the importance of the concept has been emphasized by different authors, there are very limited efforts to measure it (Choi, Seo, Scott, \& Martin, 2010). Studies are even sparser when it comes to South East Europe. Therefore, the purpose of this paper is to present a way of measuring organizational alignment and show an example of such measurement in an organization from the Information and Communication Technology (ICT) sector in the Republic of Macedonia. The importance of the paper is twofold. First, it presents a relatively new theoretical model for measuring organizational alignment developed in South East Europe (Limani, Tomovska-Misoska, Bojadjiev, 2015; Tomovska Misoska, Bojadziev, Stefanovska \& Nikolovska, 2011). This is important as organizational culture is influenced by the national culture (Hofstede, Neuijen, Ohayv, \& Sanders, 1990) and instruments measuring the organizational culture and alignment should be tailored to the broader cultural context (Choi at.al., 2010). Secondly, it provides an outline of such measurement in an ICT sector which is a fast developing and high-performing sector, where the organizational culture is connected to innovation and success (Hung, Chung \& Lien, 2007). The paper will start by presenting the theoretical background and elaborate a new theoretical framework, Vox Organizationis, for looking at alignment. The methodology followed by the results in one ICT company in the Republic of Macedonia will be elaborated. At the end the conclusion and recommendations for the future will be provided.

\section{Understanding Organizational Alignment}

Many authors tried to explain and outline what organizational alignment encompasses. Authors used notions from human resource development (Alagaraja, 2013) and strategy and organization theory (Powell, 1992). Some of the earliest notions of alignment can be found in the congruence model which pointed that activities and processes should be designed to increase performance and the fit between various components of the system is what matters most (Nadler \& Tushman, 1989). Following this notion, many different viewpoints developed, emphasizing different elements that can be part of the organizational alignment and different processes and connections between different elements. However most models of alignment emphasize congruence, fit and consistency (Schneider, et.al., 2003) in terms of the level of systemic agreement between different elements and forces within the organization (Semler, 1997). 


\section{Macrothink}

Business and Economic Research

ISSN 2162-4860

2016, Vol. 6, No. 2

For example, one conceptualization of organizational alignment emphasizes the degree to which organizational design, strategy, and culture are combined and are aimed at attaining the organization's strategy (Semler, 1997). Therefore the organization and its leadership should constantly create a climate in which all of the six aspects of alignment (process, reward system, values, norms, performance and environment) can achieve high level of internal performance. Labowitz (2004) supports this line of thinking by accentuating that "alignment is an optimal state in which strategy, employees, customers, and processes work in concert" (p.30). Along the same lines Merron (1994) outlines the following internal elements of alignment: purpose, strategy, objectives, structure, and culture, which should be working together and in the same direction. Powell (1992) on the other hand, views alignment as a balance between organizational differentiation and integration.

One comprehensive theory that also enables development of designs for testing organizational alignment has been proposed by Tosti (2007). The model proposes that the results of the organizations depend on the practices of the people within the organization as much as they depend on the processes followed in the organization. Therefore, the behavior of the employees coupled with the well-designed processes can provide competitive advantage and make a difference between good results and outstanding results. As such, alignment of the processes as the formal side of the organizational functioning and the practices as non-formal side of the organizational functioning are equally important. Those two aspects are basis of the overall alignment of the organization. Therefore the goals processes and tasks on one side and the values, practices and behaviors on the other side are important aspects of the model for organizational alignment (see Figure 1). Looking back at Semler's theory (1997) the structure and organizational design including the policies of the organization can be considered the formal side of the operational functioning. At the same time, the organizational culture and leadership values can be regarded as the non-formal side of the organizational functioning.

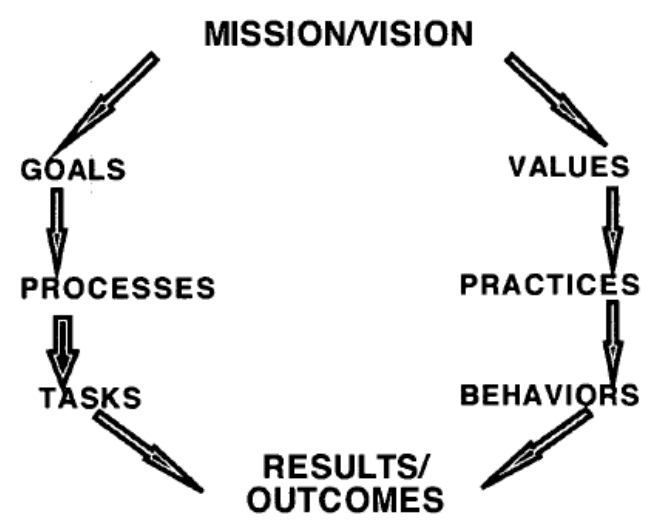

Figure 1. Organizational alignment model

Source: Tosti, 2007 
Therefore, the present paper presents a model for measuring the organizational alignment building on the theories of Semler (1997) and Tosti (2004). The paper uses a model of alignment looking at the organizational culture and leadership values on one side as non-formal part of the organizational functioning and organizational structure, strategy and policies as formal side of the organizational functioning on the other side (see Figure 2) (Limani, Tomovska-Misoska \& Bojadjiev, 2015; Tomovska-Misoska et.al. 2011). The elements of the model can be explained as:

- Organizational culture can act as a mechanism that ensures connection of the people and the organization (Freiling \& Fichtner, 2010). Organizational culture is thought to be determinant of employee behavior through the values and practices (Williams, 2002). However it is much debated concept when it comes to definitions. Most of them concentrate on the underlying values, beliefs, principles and practices for which there is common understanding between the members of an organization (Jaivisarn, 2010; Singh, 2007). Schein (2004) and Hofstede (1998) propose similar models of organizational culture based on different levels of representation and analysis of organizational culture. Hofstede (1998) views culture as an onion that has organizational practices as visible representation of culture. The second deeper level consists of heroes, symbols and rituals, whilst the third invisible layer hides the true values of the organization that can be accessed only through studying the first level. In a similar fashion Schein (2004) considers artifacts as visible representations, values and beliefs as day to day operating principles and underlying assumptions as deepest level that actually guide behavior. Most instruments for organizational culture use self-reported measures administered to employees and then use their answers to create certain numerical indexes to delineate types of organizational culture (Jex \& Britt, 2008). The instruments usually ask the members of the organization about the current behaviors and practices within the organization (Hofstede, 1998).

- Leader's values are still in the non-formal aspect of the organizational functioning. Having in mind that leaders set directions for the organization and can intentionally influence the organizational culture (Mozafarri, 2008) it becomes very important to asses them. The values set the preferences and judgements about desirable and undesirable alternatives (Semler, 1997) and can also influence the values and beliefs of the organizational members (Dull, 2010; Schein, 2004). The measurement of the values is done through asking the leaders about desirable or ideal situation in the organization (Dickson, et al., 2000; House, Quigley \& deLuque, 2010).

- Organizational structure, strategy and policies are considered the formal aspect of the organizational functioning. They define the goal-directed behavior (Semler, 1997). They set up the goals and objectives of the organization and set up the processes and tasks of the employees (Andrews a\& Beynon, 2011; Tosti \& Jackson, 1994). 


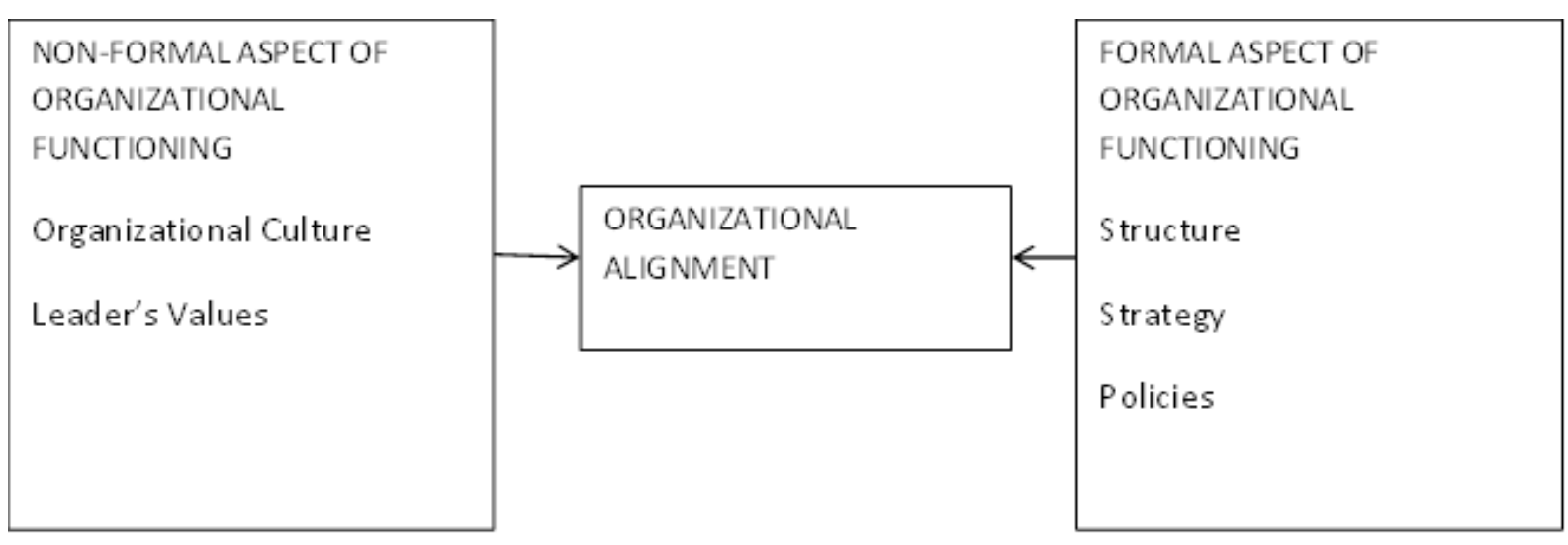

Figure 2. Vox Organizationis Model

Source: Limani, Tomovska-Misoska and Bojadjiev (2015)

These four elements of the model are measured on four dimensions connected to the organizational functioning developed through synthesis of dimensions previously used by other authors and adapting them to be used in South Eastern Europe context. The dimensions are bipolar (Tomovska-Misoska et al., 2011):

- Decision making and behavior - which is defining whether organization is leaded in bureaucratic way (behavior strictly governed by policies and procedure) or democratic way (in which decision making and behavior is governed by shared understanding and culture and direct involvement of employees in decision making processes);

- People versus task - it evaluates whether the company pays more attention and takes care of tasks (or getting the job done), or emphasizes care for the well-being of the employees and their personal satisfaction;

- Innovativeness and risk taking - whether and how company is positioning itself toward the innovations and preparedness for risk taking;

- Open versus closed system - how the company is positioning itself toward new employees and external surrounding and environment.

\section{Methodology}

The study was performed in one organization operating in the ICT sector in the Republic of Macedonia. The company is one of the oldest companies in the sector operating for more than 25 years. The company belongs to Small and Medium Enterprises sector and is a well-known brand in the Republic of Macedonia, still owned by domestic owners.

Instruments designed to measure the Vox Organizationis model were used for the data collection (Tomovska et al., 2011). The employees as well as the leaders provided answers to the instruments as suggested by Jex and Britt (2008).

The model utilizes the use of three different instruments. The first one is for the employees 
and it contains 35 questions to measure the organizational culture as one aspect of the non-formal part of organizational functioning. The questions are related to the practices and behaviors in the organization. That instrument also contained 6 demographic questions. To measure the leader's values, the four leaders in the organization also received the same 35 questions as the employees, but with accent on how would an ideal organization look like. These two instruments utilize the use of four point Likert type scale. To prevent response set some of the questions in all of the four dimensions are reverse coded. The questionnaires have the following structure: first nine questions measure the dimension decision making and behavior with high scores pointing to democratic approach; questions 10 to 17 are for the people versus task dimension where high scores indicate care for people; questions 18 to 24 refer to the dimension innovativeness and risk taking with high score meaning support of innovativeness among employees; finally questions 25 to 35 measure open versus closed system and in this dimension high score indicates more open organization.

The formal aspect of the organizational functioning was appraised through interviews with the 4 leaders in the company. The interview protocol is the third part of the Vox Organizationis model and contains questions about the structure, the strategy and the policies of the organization. The questions are again grouped into the four dimensions. The results of the interview were then calculated to determine where the formal aspect of the company's formal functioning stands in terms of the four dimensions.

After obtaining the final scores on each of the instruments they were compared to appraise the overall level of alignment. The deeper analysis was also performed for each dimension to check for particular problems in each dimension, but this analysis is not part of this paper.

In total 62 employees answered the organizational culture questionnaire. Of the total number of employees $49 \%$ were males and $51 \%$ were females. Most of the employees have been employed in the organization for more than 10 years $(31 \%)$, followed by employees working 5 to 10 years $(32 \%)$ and 1 to 5 years $(21 \%)$. The average age of the employees participating in the research was 36,5 years. Most of the employees $(73,2 \%)$ have a university degree. In addition the four leaders who are founders of the company took part as well.

\section{Results}

This section will start by presenting the results regarding the organizational culture as seen by the employees. The scores for each dimension of the model obtained from the employees are presented in Figure 3. 


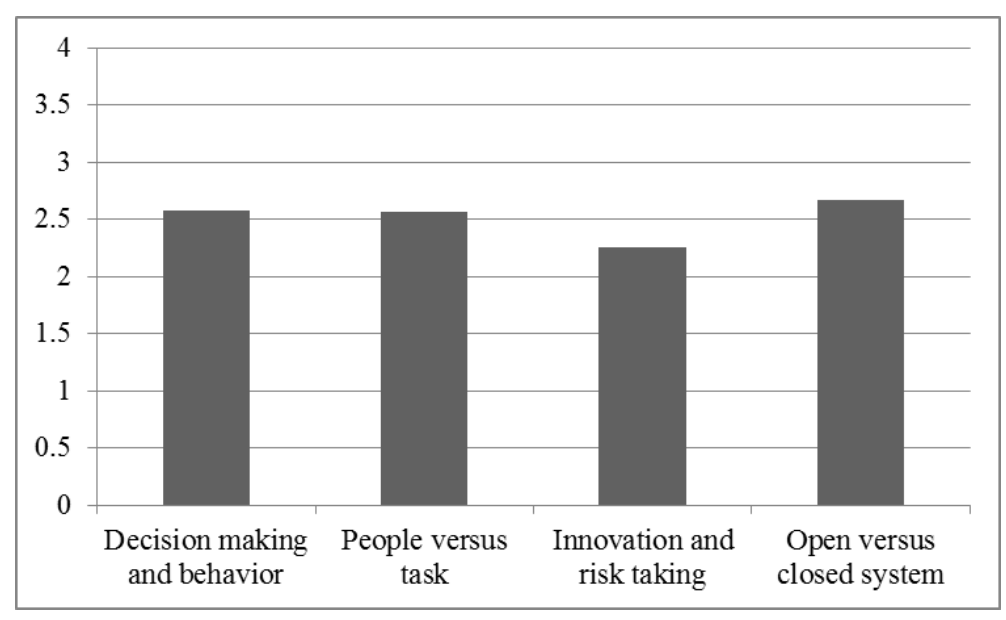

Figure 3. Organizational culture results

As it can be seen from Figure 3 the employees view the organizations as leaning towards democratic rather than bureaucratic way of functioning (2.58 out of 4.00). This means that the employees feel that they are involved in the decision making processes and their behavior is governed by shared understanding of "adequate" behavior. They do not feel that there is a need for strict guidelines and procedures to guide their behavior within the organization. The results for the dimension 'people versus task', show that the employees feel that the organization is leaning towards taking care of their well-being (2.57 out of 4.00). This does not suggest that the tasks are not completed, but in the process of their completion the company takes care of the well-being of the employees. With regards to 'innovativeness and risk taking' employees (2.25 out of 4.00) view the organization as borderline innovative and risk taking. Having in mind that this is a company form the ICT sector where constant innovation is key to success, there is scope for improvement in this area. On the fourth dimension, employees reported that they view the organization as more open than closed (2.67 out of 4) meaning that they feel support for intra-sectoral and inter-sectoral collaboration. They also feel that the organization is open towards contacts with the broader environment.

To assess the level of alignment between the two aspects of the non-formal organizational functioning the scores of the leaders' values instrument were calculated next and were then compared with the organizational culture scores on all four dimensions. The results of the comparison can give a picture to the leaders as to how well their vision of the "ideal organization" and what they strive towards, is translated in the actual behavior and practices within the organization as seen by the employees. Such comparison can point to how successful the leaders are in communicating the values and vision to the employees and in creating organizational culture aligned with their vision. The comparison of the results obtained for the leader values and organizational culture are presented in Table 1 and Figure 4. 


\section{Macrothink}

Table 1. Comparison of the organizational culture and leaders' values scores

\begin{tabular}{|l|l|l|l|l|}
\hline & $\begin{array}{l}\text { Decision making } \\
\text { and behavior }\end{array}$ & $\begin{array}{l}\text { People versus } \\
\text { task }\end{array}$ & $\begin{array}{l}\text { Innovativeness } \\
\text { and risk taking }\end{array}$ & $\begin{array}{l}\text { Open versus } \\
\text { closed system }\end{array}$ \\
\hline Leader values & 3 & 3.06 & 2.57 & 3.2 \\
\hline Org. culture & 2.58 & 2.57 & 2.25 & 2.67 \\
\hline
\end{tabular}

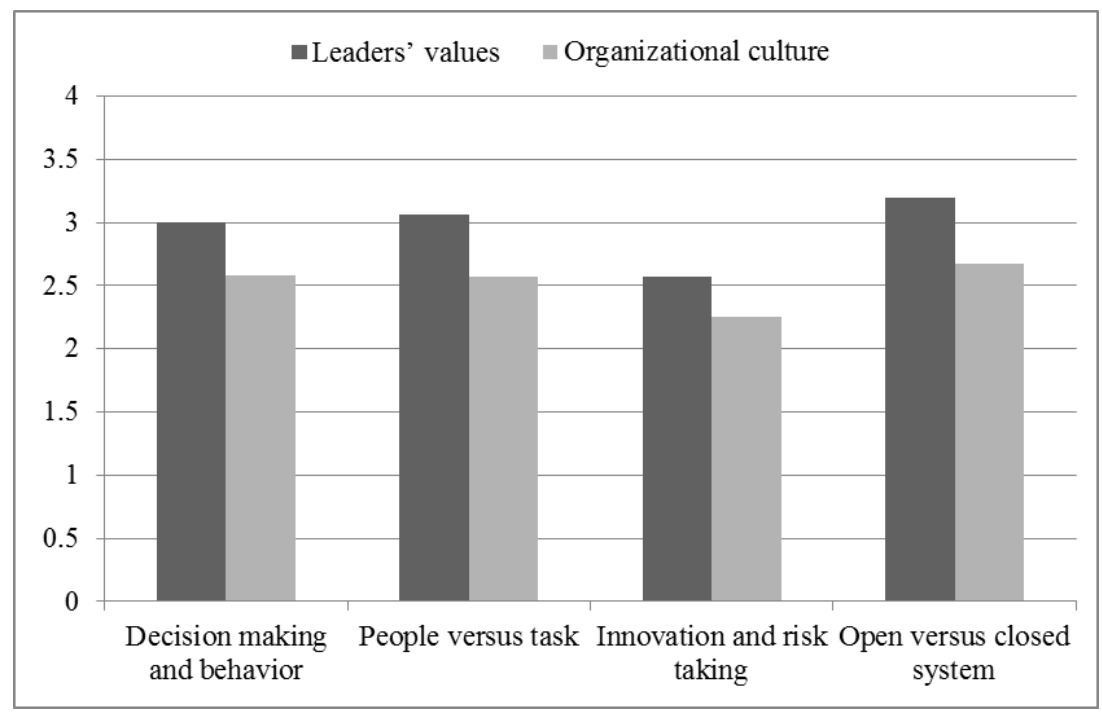

Figure 4. Comparison of Leaders' Values and Organizational Culture results

As can be seen in Table 1 and Figure 4 leaders have slightly higher appraisal on all dimensions. The results are not unexpected as the leaders are the ones that actually set up an example for the employees and can shape the organizational culture in accordance to their vision and values (Schein, 2004). In general there is good alignment in the non-formal aspect of the organizational functioning. However there might be slight improvements needed to help the employees feel that the company is more open towards innovation and risk taking as that is where the scores on the organizational culture instruments are closer to the mean and the leaders' values are higher.

After appraisal of the alignment in the non-formal aspect of the organizational functioning a comparison was made with the results obtained by the interviews with the four leaders regarding the formal aspect of the organizational functioning. This was done to appraise the overall alignment of the company. Table 2 shows side by side comparison for the overall assessment of each dimension as gathered by the three different instruments. 
Table 2. Comparison of the formal and non-formal aspect of the organizational functioning

\begin{tabular}{|l|l|l|l|l|}
\hline & $\begin{array}{l}\text { Decision making } \\
\text { and behavior }\end{array}$ & $\begin{array}{l}\text { People versus } \\
\text { task }\end{array}$ & $\begin{array}{l}\text { Innovativeness } \\
\text { and risk taking }\end{array}$ & $\begin{array}{l}\text { Open versus } \\
\text { closed system }\end{array}$ \\
\hline Leader values & Democratic & People oriented & Innovative & Open \\
\hline Org. culture & Democratic & People oriented & Borderline & Open \\
\hline Formal aspect & Bureaucratic & People oriented & Innovative & Open \\
\hline
\end{tabular}

The results show that there is good alignment in the ICT company used in this study. There are two dimensions that need slightly more attention: 'innovativeness and risk taking', and 'decision making and behavior'. Whilst the leaders strive towards encouraging innovativeness and risk taking visible in the expression of their values and the organizational documents, the employees might need slightly more encouragement in that direction.. This dimension is generally aligned but more actions or more visible expression of that commitment by the leaders in the everyday functioning might be needed to show the employees that innovating and proposing new ideas is valued in the organization. The other dimension that might need more attention is the dimension 'decision making and behavior'. Whilst the employees appraise the organization as democratic and trusting towards the employees and leaders envisage the organization as such, the formal aspects are not aligned with this. The documents existing in the organization are actually more bureaucratic and prescribe more strict decision making rules and procedures. However since the people in the organization feel differently the answer to this might be in changing of the formal functioning towards more democratic decision making policies and procedures.

\section{Conclusion}

The focus of this paper is organizational alignment which is an important aspect of the organizational functioning. Although the concept has received much attention in recent years there are limited efforts to measure the concept. As such this paper is important from a theoretical viewpoint as it presents a model for measuring organizational alignment developed in South Eastern Europe. It also illustrates the applicability of the model in practice by providing data from one ICT company in the Republic of Macedonia. The results point to a high degree of alignment within the institution and outline areas of improvement. However the usefulness of the instrument is not only theoretical it is also practical. It enables the companies to discover areas for future improvement in achieving better organizational alignment. By looking at the alignment in the different dimensions the leaders can gain insight for future actions. The model also allows deeper analysis into more concrete measures by comparisons based on each questions to uncover specific misalignment issues. This will enable tailor-made approach to changes for every company using the model, making Vox Organizationis a useful diagnostic tool.

Although this study shows the applicability and the usefulness of the Vox Organizationis model, it is limited in scope as it uses data from only one company. Future studies are needed to test the validity of the model. These studies should be done in different sectors and in 
different countries to enable comprehensive testing of both theoretical value and practical applicability.

\section{References}

Alagaraja, M. (2013). Mobilizing organizational alignment through strategic human resource development. Human Resource Development International, 16(1), 74-93.

http://dx.doi.org/10.1080/13678868.2012.740794

Andrews, R., \& Beynon, M. J. (2011). Organizational form and strategic alignment in a local authority: A preliminary exploration using fuzzy clustering. Public Organization Review, 11, 201-218. http://dx.doi.org/0.1007/s11115-010-0117-4

Biggs, A., Brough, P., \& Barbour, J. P. (2014). Strategic alignment with organizational priorities and work engagement: A multi-wave analysis. Journal of Organizational Behavior, 35, 301-317. http://dx.doi.org/10.1002/job.1866

Choi, Y. S., Seo, M., Scott, D., \& Martin, J. (2010). Validation of the Organizational Culture Assessment Instrument: An application of the Korean version, Journal of Sport Management, 24, 169-189. Retrieved from:

http://digitalcommons.wayne.edu/cgi/viewcontent.cgi?article=1002\&context=coe_khs

Crots, J. C., \& Ford, R. C. (2008). Achieving service excellence by design: The organizational alignment audit. Business Communication Quarterly, 71(2), 233-240.

http://dx.doi.org/10.1177/1080569908317319

Denison, D. R., \& Mishra, A. K. (1989). Organizational culture and organizational effectiveness: A theory and some preliminary empirical evidence. Academy of Management Proceedings, 1, 168-172. http://dx.doi.org/0.5465/AMBPP.1989.4980714

Dickson, M. W., Aditya, R. N., \& Chhokar, J. S (2000). Definition and interpretation in crosscultural organizational culture research. In N.M. Ashkanasy, C.P.M. Wilderom \& M.F. Peterson (Eds.), Handbook of organizational culture and climate (pp. 447-464). Thousand Oaks: Sage.

Dull, M. (2010). Leadership and organizational culture: Sustaining dialogue between practitioners and scholars. Public Administration Review, 17(6), 857-866. Retrieved from: http://www.jstor.org/stable/40927102

Freiling, J., \& Fichtner, H. (2010). Organizational culture as the glue between people and organization: A competence-based view on learning and competence building. German Journal of Research in Human Resource Management, 24(2), 152-172.

http://dx.doi.org/10.1688/1862-0000_ZfP_2010_02_Freiling

Hofstede, G. (1998). Attitudes, values and organizational culture: Disentangling the concepts, Organization Studies, 19(3), 477-492. http://dx.doi.org/10.1177/017084069801900305

Hofstede, G., Neuijen, B., Ohayv, D. D., \& Sanders, G. (1990) Measuring organizational cultures: A qualitative and quantitative study across twenty cases, Administrative Science 
Quarterly, 35, 286-318.

House, R. J., Quigley, N. R., \& deLuque, M. S. (2010). Insight from project GLOBE: Extending global advertising research through a contemporary framework. International Journal of Advertising, 29(1), 111-139. http://dx.doi.org/10.2501/S0265048709201051

Hung, Y. Y., Chung, T., \& Lien, B. Y. (2007). Organizational process alignment and dynamic capabilities in high-tech industry. Total Quality Management, 18(9), 1023-1034.

http://dx.doi.org/10.1080/14783360701594154

Jaivisarn, V. (2010). How organizational culture of Japanese multinationals in Thailand influences Japanese-speaking Thai employees' organizational commitment. Journal of International Business and Economics, 10(1), 106-120.

Jex, S. M., \& Britt, T. W. (2008). Organizational psychology: A scientist-practitioner approach (2nd ed.). Hoboken: John Wiley and Sons.

Labovitz, G. H. (2004). The power of alignment: How the right tools enhance organizational focus. Business Performance Management, 30-34. Retrieved from: http://web.a.ebscohost.com/ehost/pdfviewer/pdfviewer?vid=5\&sid=64d1f3d4-2a84-4910-9f7 7-cd9e98439caa\%40sessionmgr4006\&hid=4201

Limani, A., Tomovska-Misoska, A., \& Bojadjiev, M. (2015). Organizational alignment as a model of sustainable development in the public sector in the Republic of Macedonia. Journal of Sustainable Development, 5(12), 51-68.

Retrieved from: http://www.fbe.edu.mk/JoSDv12.pdf

Nadler, D, A,, \& Tushman, M, L, (1989). A model for diagnosing organizational behavior: Applying a congruence perspective. In D. A. Nadler, M. L. Tushman \& C. O'Reilly (Eds.) The management of organizations: Strategies, tactics, analyses (pp. 91-106). New York: Harper \& Row.

Merron, K. A. (1994). Creating TQM organizations. Quality Progress, 27(1), 51-54.

Mozaffari, F. A. (2008). A study of relationship between organizational culture and leadership. International Conference on Applied Economics, 679-688. Retrieved from: http://faculty.mu.edu.sa/public/uploads/1360858719.3627organizational\%20cult180.pdf

Powell, T. C. (1992). Organizational alignment as competitive advantage. Strategic Management Journal, 13, 119-134. http://dx.doi.org/10.1002/smj.4250130204

Schein, E. H. (2004). Organizational culture and leadership. San Francisco: Jossey Bass.

Schneider, B., Hayes, S. E., Lim, B., Raver, J. A., Godfrey, E. G., Haung, M., ... Ziegert, J. C. (2003). The human side of strategy: Employee experience of strategic alignment in a service organization, Organizational Dynamics, 32(2) 122-141.

http://dx.doi.org/10.1016/S0090-2616(03)00014-7

Semler, S. W. (1997). Systematic agreement: A theory of organizational alignment. Human 
Resource Development Quarterly, 8(1), 23-40. Http://dx.doi.org/10.1002/hrdq.3920080105

Singh, K. (2007). Predicting organizational commitment through organization culture: A study of automobile industry in India. Journal of Business Economics and Management, 8(1), 29-37.

Tomovska Misoska, A., Bojadziev, M., Stefanovska, M., \& Nikolovska, Z. (2011). Vox organizationis - theoretical basis and methodological considerations in the development of an instrument for organizational culture. Munich Personal RePec Archive Working Paper, Retrieved from: http://mpra.ub.uni-muenchen.de/42571/.

Tosti, D. T. (2007). Aligning the culture and strategy for success. Performance Improvement, 46(1), 21-25. http://dx.doi.org10.1002/pfi.035

Tosti, D., \& Jackson, S., (1994). Alignment: How it works and why it matters. Training, 31, 58-64.

Williams, S. L. (2002). Strategic planning and organizational values: links to alignment. Human Resource Development International, 5(2), 217-233.

Http://dx.doi.org10.1080/13678860110057638

\section{Appendix}

Appendix 1. Instruments for the Vox Organziationis Model

Non-formal part (organizational culture and leaders values) questions

\begin{tabular}{|l|}
\hline Decision making and behavior \\
\hline The organization has clear "rules of the game" \\
\hline There is an atmosphere of trust in this organization \\
\hline $\begin{array}{l}\text { When changes are made, the decisions are openly and on time communicated to the relevant } \\
\text { parties }\end{array}$ \\
\hline Leaders and managers consult with subordinates in the decision making process \\
\hline The organization has written policies and procedures*** \\
\hline Achieving the results is more important than following the procedures \\
\hline The decisions are centralized at the top*** \\
\hline $\begin{array}{l}\text { The employees are trusted to act according to organizationally accepted norms and standards } \\
\text { in situations not governed by organizational rules and procedures }\end{array}$ \\
\hline There is shared understanding of the appropriate behavior in the organization \\
\hline People-Task \\
\hline $\begin{array}{l}\text { The organization provides employees with opportunity for professional development and } \\
\text { growth }\end{array}$ \\
\hline
\end{tabular}


The organization takes care about the social atmosphere and employee relations

The organization respect its employees and treats them in a consistent and fair manner

The organization is only interested in the work people do***

The organization considers employee's private lives as their own business***

The organization pays little attention to physical work environment***

The management is stingy with small things***

Employees receive timely feedback about their performance ( formal or informal)

\section{Innovativeness and risk taking}

The organization encourages experimenting and trying new things

Employees are encouraged to develop new and original ideas and/or products

Employees are encouraged "not to rock the boat"***

The organization considers innovation and appropriate level of risk taking as a way to build long term sustainability

The organization cherishes stability as a prerequisite for the long term sustainability***

The organization does not take risks, it uses tried and tested approach***

Employees and the organization try to be pioneers

Open-closed system

The organization encourages intra-departmental collaboration

The organization encourages inter-department collaboration

The organization encourages collaboration with customers and/or suppliers

The performance management system supports group work

The organization strives to expand in markets

The organization invests in learning new things

The organization does not have special ties with local community***

The organization and people are closed and secretive***

In this organizations new employees need more than a year to feel at home ${ }^{* * *}$

The organization puts emphasis on meeting customer needs

The organization nurtures positive collaboration with other companies, even if they are competitors

*reverse coded questions

Formal part questions 


\section{Decision making and behavior}

Does the organization have a formal strategic planning process (excluding the budget planning)?

Does the organization have a strategic plan?

What is the strategic plan time frame?

Do you have action plans resulting from the strategic plan?

Do the action plans have clear goals for every employee, time frames and KPIs?

Do the managers control their employees concerning the achievement of the action plan goals more than 4 times per year?

Who is involved in the process of drafting the strategic plan?

Who is involved in the process of drafting the action plans (if any)?

Who is involved in the process of drafting other bylaws and/ or procedures?

Does the organization have a formal organizational structure?

Does the organization have clearly delegated duties/responsibilities for each employee?

Is there a provision/bylaw which clearly specifies the level of freedom in decision making for decisions related to his/her workplace?

The leader consults his/her employees in the decision making process.

If yes, is there a written procedure according to which the employees can express their opinion to the management?

Are all bylaws and procedures distributed to all employees?

Who makes the decision whether the decisions are going to be distributed or not, and who decides to which employees are they going to be distributed?

Is there a bylaw according to which an employee may be penalized for not following the procedure, even though he/she managed to achieve the desirable result (KPI)?

People versus task

Does the strategic plan or any other formal document addresses some of these aspects:

Working conditions of the employees (physical conditions, workplace protection, etc.)

Work-life balance (flexible working hours, absences/leaves for personal reasons...)

Social relationships in the company and organizational climate (employees' relations, management, mobbing etc.)

Do you feel that your current strategic plan reflects "the best ideas" of your employees?

Do you believe you have a clear vision for the future and means of achieving that vision which is shared by all employees? 
Does the organization have bylaws/procedures which include trainings or professional development plans for the employees?

Does the company stimulate its employees to professionally develop and improve themselves through providing financial or other types of aid (financial aid, flexible working time, reduced working hours and the like)?

Does the company have a formal process for performance management?

Are the employees comprehensively informed about the system for performance management, i.e. the way the evaluation is conducted and by which criteria they are evaluated?

Are the employees regularly informed about the results from the evaluation system?

Innovativeness and risk taking

Does the company have a system for rewarding the innovativeness of its employees?

Does the company have a system/bylaw/procedure according to which the employees can present their ideas for introduction of new products or services, improvement of the existing ones or improving the production process etc.?

Does the strategic plan include some type of innovativeness (for example, market expansion, launching new products and/ or services, targeting new clients, etc.)?

\section{Open versus closed system}

Does the strategic plan or other documents include activities which require inter-departmental cooperation or involvement of multiple departments?

Does the strategic plan or other documents foster/encourage teamwork?

Does the employees' reward system contain part for rewarding teamwork?

Does the strategic plan or other documents include parts on internal communication processes?

Does the strategic plan or other documents include parts which focus on satisfying customers'/clients' needs?

Does the strategic plan or other documents include parts on cooperation with other organizations/ companies (competition, suppliers, other related stakeholders etc.)?

Does the strategic plan or other documents include parts on collaboration with the local community (both governmental and non-governmental institutions etc.)?

Is the company a member of any organization (chamber, international organization and thus like)?

Does the strategic plan or other documents include part on improving the employees' loyalty (for example, reducing employee turnover)?

Does the company have a formal system for orientation and induction of new employees? 


\section{Copyright Disclaimer}

Copyright for this article is retained by the author(s), with first publication rights granted to the journal.

This is an open-access article distributed under the terms and conditions of the Creative Commons Attribution license (http://creativecommons.org/licenses/by/3.0/). 